

\section{SOBRE OS AUTORES}

\section{Lisiane Ilha Librelotto | lisiane.librelotto@gmail.com}

Lattes: http://lattes.cnpq.br/7269509913517969

Engenheira Civil. Especialista em Gestão da Qualidade (1997). Mestre e doutora em Engenharia de Produção UFSC. Professora Adjuntana UFSC do curso de Arquitetura e Urbanismo - CTC/UFSC. Líder do Grupo de Pesquisa VirtuHab. Editora da Revista Mix Sustentável. Organizadora do evento ENSUS - Encontro de Sustentabilidade em Projeto. Orienta Mestrado e Doutorado no PósARQ.

Paulo Cesar Machado Ferroli | pcferroli@gmail.com

Lattes: http://lattes.cnpq.br/0328950798412598

Engenheiro Mecânico. Especialista em Gestão da Qualidade (1997). Mestre e doutor em Engenharia de Produção pela UFSC. Professor adjunto IV do CCE-EGR, curso de Design da UFSC e coordenador de extensão do Centro de Comunicação e Expressão. Vice-líder do Grupo de Pesquisa VirtuHab. Editor da Revista Mix Sustentável. Organizador do evento ENSUS - Encontro de Sustentabilidade em Projeto. 


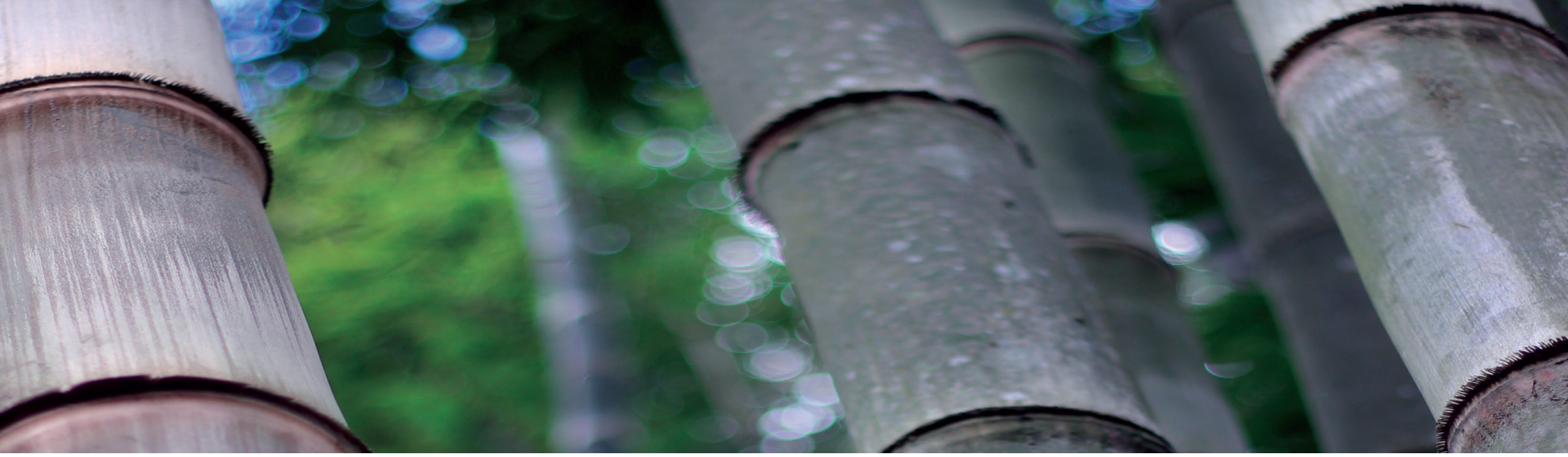

\title{
Materiais e sustentabilidade: aplicações do bambu em arquitetura, design e engenharia
}

\author{
Materials and sustainability: bamboo \\ applications in architecture, design and \\ engineering
}

Lisiane Ilha Librelotto, Paulo Cesar Machado Ferroli

\section{Resumo}

O bambu está entre os materiais que mais atraíram atenção nos últimos anos. Com cerca de 1000 espécies, muitas com condições para os mais diversos usos, é autorregenerável, apresentando uma relação excelente de custo - benefício. As aplicações são as mais variadas possíveis, de galpões, oficinas e treliças (arquitetura), conexões estruturais (engenharia), móveis e utensílios (design) até produtos de design de moda (óculos). Contudo, ao mesmo tempo em que pesquisas científicas de qualidade são elaboradas, muitos experimentos são empíricos, guiados pela tentativa, com fracasso ou sucesso. 0 pesquisador da área deve tomar cuidado com as fontes consultadas, verificando o nível de confiabilidade nos resultados divulgados. Este artigo apresenta uma síntese sobre os usos do bambu, classificação, propriedades e considerações sobre seu emprego.

Palavras-chave: Sustentabilidade; Materiais; Bambu; Design.

\section{Abstract}

Bamboo is among the materials that attracted the most attention in recent years. It has 75 main species and a self-regenerating material. It has an excellent cost - benefit relationship. The applications are as varied as possible: sheds, workshops and trusses (architecture), structural connections (engineering), furniture and utensils (design) and to fashion design products (glasses). However, at the same time that quality scientific research is done, there is also a high degree of amateur research. The researcher of the area should be careful about the sources consulted. You should check the level of reliability of the reported results. This article presents an overview of the bamboo's use in product design. The data originated in events and scientific journals in recent years. 


\section{INTRODUÇÃO: PERSPECTIVAS A CERCA DE NOVOS MATERIAIS}

De acordo com Lefteri (2017, p. 74), "o bambu tem atraído tanta atenção nos últimos anos que poderia ser sugerido como o material do século XXI".

Carbonari e outros (2017) explicam que a fabricação de produtos com materiais tradicionais mobiliza consideráveis recursos financeiros e demonstra, em seu trabalho, as vantagens econômicas do uso do bambu. 0 estudo é acompanhado de testes que permitiram a obtenção de propriedades mecânicas de várias espécies de bambu.

Tido como um material alternativo inovador o bambu está, de modo quase consensual, classificado nesta modalidade junto a outros materiais, que englobam, por exemplo, fibra de coco, casca de árvore, couro de peixe, junco, cânhamo, palha de trigo e fibras de cenoura (para citar alguns). Estes materiais recebem essa denominação de alternativos porque, ao contrário dos chamados materiais tradicionais (ou convencionais), estão em processo de experimentação ou ainda não possuem normas técnicas nacionais correntes que orientem seu uso.Por este motivo, projetar utilizando materiais alternativos não é tão seguro quanto projetar usando materiais convencionais. Ao utilizar metais, madeiras, plásticos ou cerâmicas, o designer terá a seu dispor uma quantidade muito grande de livros técnicos de autores consagrados, além de manuais, normas ABNT e inúmeros casos de uso do material nos mais diversos ambientes e condições de uso. Ou seja, tem a sua disposição informações que já foram testadas e comprovadas em uma enorme gama de aplicações.

Autores como Callister Júnior e Rethwisch (2016), cujo livro chegou a nona edição, apresentam uma visão completa detalhada sobre metais, madeiras, cerâmicas e plásticos e são utilizados em praticamente todos os cursos de engenharia do país.

Na área de metais ferrosos, pouco não se encontra na sétima edição de Chiaverini (2012), que apresenta detalhadamente a influencia dos elementos químicos adicionados a liga base $\mathrm{Fe}-\mathrm{C}$, além de tratamentos térmicos e superficiais; quando o assunto é plástico, as obras de Eloisa 
Mano são referências usadas em todos os cursos universitários do país, e o Instituto Avançado do Plástico (2017) oferece uma vasta coletânea de obras técnicas, abordando plásticos commodities, industriais, polímeros de alta performance, aditivos, blendas e compósitos poliméricos.

A madeira também é contemplada em muitas publicações, e no design as referências usadas são Pereira (2013), que apresenta um panorama geral com características técnicas e estéticas de árvores brasileiras e SENAI (2014), que, embora com ênfase no design de mobiliário, é uma importante fonte de consulta.

Tem-se ainda autores como Ashby e Johnson (2014), que além do livro abrangente com todos os grupos de materiais, desenvolveram em parceria com outros pesquisadores, o software Granta Design (2017), que dentre outras coisas permite ao projetista uma análise visual comparativa entre atributos quantitativos e qualitativos de diversos materiais (metais não ferrosos, ferrosos, polímeros, fibras, cerâmicos etc.).

Revistas científicas, anais de eventos e bancos de teses e dissertações, complementam o estado da arte dos materiais, apresentando as principais novidades do setor, com a constante inclusão de novos elementos químicos na busca de ligas metálicas e poliméricas de alta durabilidade e resistência, preferencialmente com baixo custo e peso. Engenheiros e designers que tiveram sua graduação nos anos 1990 ou menos, precisam estar atentos às mudanças no mercado de materiais, onde a inclusão de elementos como Escândio (Sc), Estrôncio (Sr), Zircônio (Zr), Nióbio (Nb), Neodímio (Nd) dentre outros ligados com Alumínio (Al) e outros metais mais conhecidos estão se tornando tão comuns e usuais como as ligações metálicas mais tradicionais envolvendo Titânio (Ti), Vanádio (V), Cromo (Cr), Manganês (Mn), Níquel (Ni), Cobre (Cu), Zinco (Zn), Molibdênio (Mo) e assim por diante.

Do mesmo modo, as novidades científicas no campo dos plásticos são documentadas em elevada quantidade. Publicações técnicas de indústrias e universidades como, por exemplo, a revista mensal Plástico Industrial (2017), entre outras, apresenta regularmente novidades de novas formulações poliméricas, blendas, misturas, compósitos, copolimeros e aditivos. Uma vez que os produtos fabricados com materiais 
poliméricos não biodegradáveis estão atualmente sofrendo uma série de restrições ambientais, os biopolímeros, polímeros biodegradáveis e os "polímeros verdes" tem se tornado um mercado em expansão.

O mesmo vale para as cerâmicas avançadas, cermets e compósitos. Fabricadas de óxidos, carbetos, nitretos etc. as técnicas de metalurgia do pó elevaram estes materiais a um nível de utilização que provocam o barateamento e consequentemente o acréscimo de oferta de produtos fabricados.

No entanto, essa é a realidade que se tem quando se considera o grupo de segurança, ou seja, utilizando-se materiais tradicionais. $\mathrm{E}$ diferente quando se consideram os chamados materiais alternativos, que ainda carecem de informações precisas e/ou confiáveis. Enquanto que as pesquisas relacionadas aos denominados materiais tradicionais exigem laboratórios de última geração, ambiente controlado e mãode-obra especializada, além de valores elevados de investimento, essa não é necessariamente a realidade quando se trata de materiais alternativos.

A manipulação laboratorial ou fabril de elementos químicos adicionados em ligas de aço, alumínio, ligas poliméricas ou cerâmicas inibe ou mesmo inviabiliza tentativas amadoras. Isso não ocorre com a manipulação de materiais como casca de árvore, juta, fibra de coco, cana de açúcar, crina de cavalo e mesmo o bambu. A facilidade de processamento e obtenção do material, possibilidade de utilização de maquinário comum de oficina, falta de normalização ABNT padronizando processos e acesso ao material in natura facilitam a experimentação.

Outro aspecto a ser observado diz respeito ao tempo de pesquisa e desenvolvimento a que o material está submetido. Enquanto que os materiais tradicionais possuem um histórico de mais de 200 anos de pesquisas científicas, muitos dos resultados apresentados para os materiais alternativos contam de poucos anos, no máximo algumas décadas. Claro que não se pode desconsiderar as experiências construtivas da arquitetura vernacular com materiais naturais, um conhecimento esquecido no tempo, cujos exemplares ainda podem ser encontrados. 
Este artigo tem por objetivo discutir a inclusão do bambu (principalmente) e outros materiais denominados de alternativos no projeto de design, engenharia e arquitetura. Apresenta uma visão geral das propriedades do material, histórico, cadeia produtiva no Brasil, principais pesquisas em desenvolvimento na área, usos e aplicações do material com base nas publicações recentes de periódicos e eventos científicos, em processo de revisão bibliográfica em bancos de teses e dissertações e portal de periódicos.

\section{HISTÓRICO DO MATERIAL}

Os primeiros materiais utilizados pelo homem eram aqueles que poderiam ser obtidos facilmente na natureza. Assim usaram a pedra, a terra, a madeira e o bambu.

O bambu é utilizado há milênios para a construção de estruturas de casas, paredes, telhas, portas e janelas, mobiliário, utensílios de cozinha, objetos de decoração, cercas, pontes, embarcações.

Em países da Ásia e na América do Sul, como os sítios arqueológicos no Equador, mostram que o bambu é utilizado há cerca de cinco mil anos, primeiramente pelos indígenas. Em países como o Equador, Colômbia e Costa Rica, onde a pesquisa e utilização do bambu estão bastante avançadas, existem até programas de habitações populares em bambu.

Se o processo de tratamento do bambu for realizado de maneira adequada, as construções podem ter uma grande durabilidade, como visto em algumas construções centenárias.

Bicicletas feitas com o bambu estão sendo comercializadas mundialmente por serem ecologicamente corretas e de baixo custo, o que pode favorecer pessoas de países subdesenvolvidos, principalmente na África. Soares (2013) traz uma revisão histórica do uso do Bambu, e mostra exemplos interessantes como avião de Santos Dumond (encomendado em 1902, e que foi aos céus em 1906) 14 Bis, construído com seda, bambu e alumínio e posteriormente o Demoiselle, com sua estrutura constituída basicamente por bambu. (Partes A e B da Figura 1). 


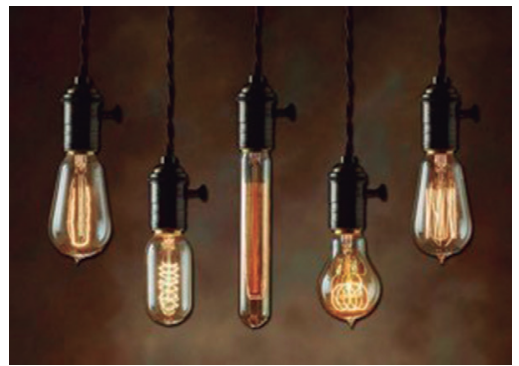

Figura 2: Lâmpadas incandescentes com filamento de bambu. Fonte: decor.com.br (2017).

\section{Avião Demoiselle de Santos} Dumond, de 1909

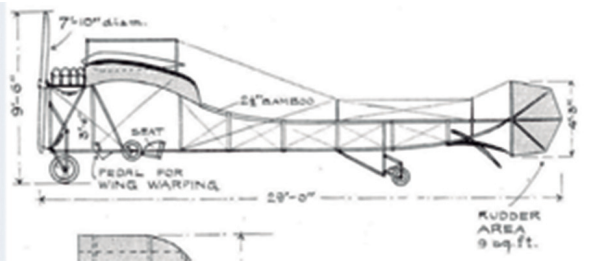

Avião Fritz 1914

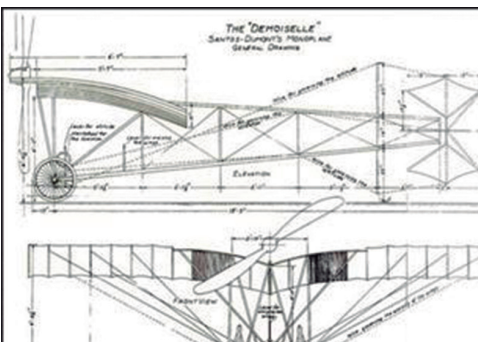

Figura 1: Aviões com estrutura em bambu. Fonte: Flying Machines (2017).

Outro exemplo interessante é o filamento da lâmpada incandescente, descoberto por Thomas Alva Edison em 1879, que utilizou filamento de carvão e posteriormente de bambu (filamentos de carbono). A lâmpada de filamento de bambu (Figura 2) carbonizado foi a que teve melhor rendimento e durabilidade nos testes iniciais e posteriormente foi substituído pela celulose e ligas metálicas (BURINI JÚNIOR, 1993). As lâmpadas com filamento de carbono estão de volta ao mercado, em 2017, pois possuem uma iluminação diferenciada para interiores.

No Brasil, os primeiros usos do bambu remontam a ferramentas e na construção de habitações. A tribo Xingu foi uma das que tradicionalmente utilizou-se deste material para suas construções. A Figura 3 mostra um modelo construído na UnB (Universidade de Brasília), em oficina ministrada pelo índio Xinguano, Maniwa Kamayurá.
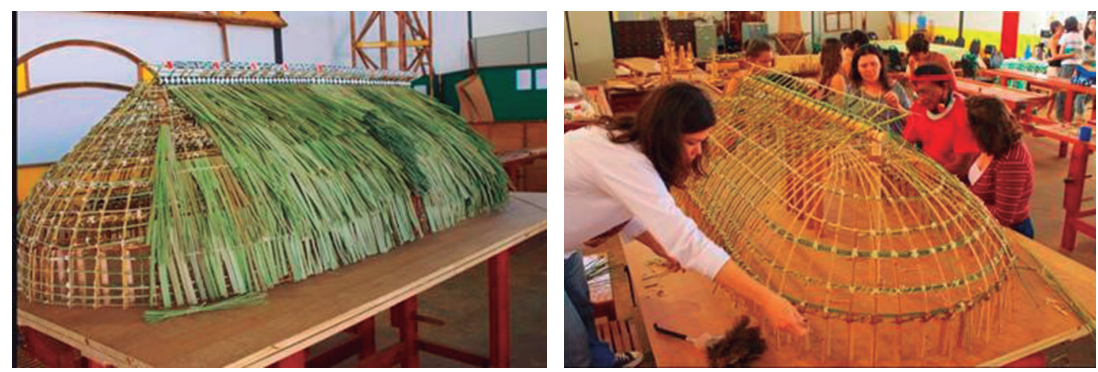

Figura 3: Oficina ministrada na UnB para reprodução da casa indígena. Fonte: Veraldo (2017).

Outras formas de construção com o material são registradas também nas tribos Tupi, Guaranis, Jês, Carajás e Xavantes. (Arquitetura do Brasil, 2017). No mundo uma das construções mais antigas realizadas com o 
bambu é o TAJ Mahal. A imagem da Figura 3 mostra sua cúpula coberta por um andaime externo de bambus para protegê-la de bombardeios durante a segunda guerra mundial. A parte $B$ da figura mostra a construção hoje; as partes C e D da figura ilustram a estrutura em bambu da flor de lótus, que constitui a cúpula das torres.

\section{MATERIAIS NO PROJETO}

Bibliografias sobre o tema (INBAR, 2016 e Ghavami, 2005) identificam entre 1200 a 1500 espécies de bambu em todo o mundo. Cerca de 250 seriam endêmicas brasileiras.

De acordo com Recht e Wetterwald (2017) o bambu possui um "sistema subterrâneo de rizomas, os colmos e os galhos". Todas estas partes são formadas do mesmo princípio; uma série alternada de nós e entrenós. Com o crescimento do bambu, cada novo internó é envolvido por uma folha caulinar protetora, fixada ao nó anterior no anel caulinar.

Os nós são massivos pedaços de tecido, compreendendo o anel nodular, o anel da bainha e geralmente uma gema dormente. Estas gemas são o local de emergência do novo crescimento segmentado (rizoma, colmo ou galho).

Manzini (1993) explicou que o surgimento constante de novos materiais obriga a uma contínua reorganização da classificação dos materiais. 0 passar dos anos aumentou a importância dos materiais dentro do design. Somente considerando os últimos três anos, foram lançados pelas principais editoras brasileiras 23 livros cujo tema é materiais e processos, relacionados ao design, arquitetura ou engenharia.

As tentativas de classificação continuam sendo importantes, pois objetivam organizar propriedades, pontos fortes, limitações e exemplos de uso, facilitando o processo de seleção e materiais.

Ferroli e outros (2017) apresentam uma tabela classificatória de materiais (Tabela 1), com o intuito de facilitar o processo de seleção. Serve de base para o início do processo, cujo método está demonstrado no site da Materioteca da UFSC, (http:/materioteca.paginas.ufsc.br/) e está em constante adaptação.
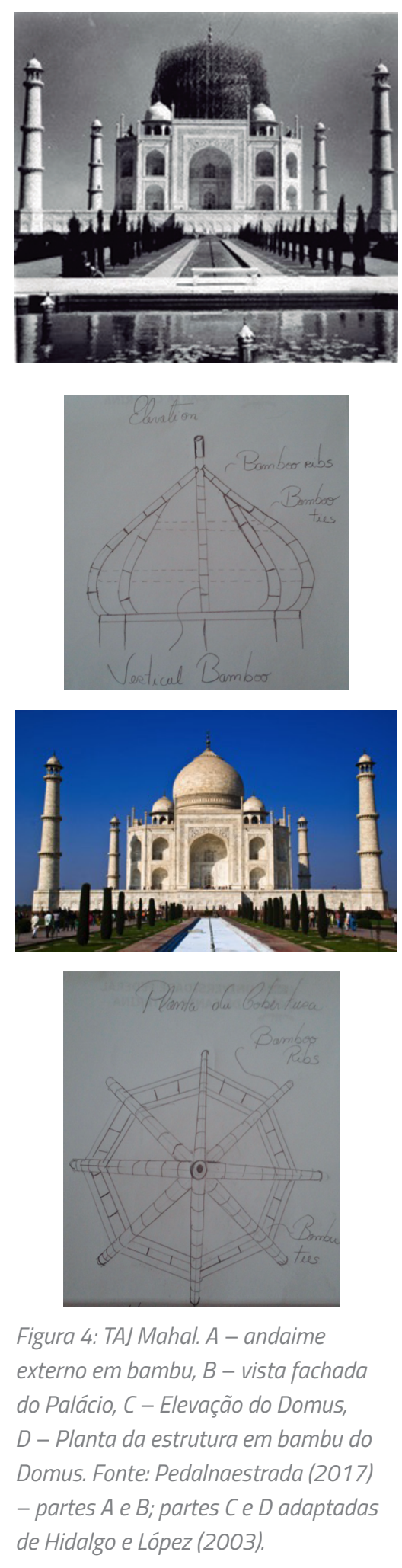
Tabela 1 - Classificação de materiais tendo por base a FEM Ferramenta de Escolha de Materiais.

\begin{tabular}{|c|c|}
\hline QUADRO 1 & Madeiras naturais, transformadas e para revestimentos \\
\hline QUADRO 2 & Papéis (comum), cartões e papelão \\
\hline QUADRO 3 & Metais ferrosos (aços e ferros fundidos) \\
\hline QUADRO 4 & Metais não ferrosos (ligas) \\
\hline QUADRO 5 & Materiais sinterizados - Metalurgia do pó \\
\hline QUADRO 6 & $\begin{array}{l}\text { Polímeros- plásticos (commodities, de engenharia, } \\
\text { de alta performance) }\end{array}$ \\
\hline QUADRO 7 & Polímeros - blendas \\
\hline QUADRO 8 & Polímeros - adesivos \\
\hline QUADRO 9 & Cimentos, concretos e agregados \\
\hline QUADRO 10 & Cerâmicas (comuns) e vidros \\
\hline QUADRO 11 & $\begin{array}{l}\text { Materiais naturais (bambu, gemas, pedras, couro, lã, } \\
\text { e outros) }\end{array}$ \\
\hline QUADRO 12 & $\begin{array}{l}\text { Fibras naturais (rami, sisal, juta, côco etc.) e } \\
\text { fibras artificiais }\end{array}$ \\
\hline QUADRO 13 & Borrachas naturais e sintéticas \\
\hline QUADRO 14 & Óleos e graxas \\
\hline QUADRO 15 & Tintas e vernizes \\
\hline QUADRO 16 & Materiais de nano tecnologia \\
\hline QUADRO 17 & Compósitos avançados \\
\hline QUADRO 18 & Outros materiais \\
\hline
\end{tabular}

Fonte: Ferroli e outros (2017)

As tabelas são complementadas por amostras físicas, que permitem ao usuário a experimentação tátil, que complementa todas as demais informações visuais. A Figura 4 ilustra um conjunto de amostras da materioteca. 
Na Tabela 1 observa-se que o bambu, material tema deste artigo, encontrase listado junto aos materiais naturais do Quadro 11 e separado das madeiras.

Desta forma percebe-se que a Tabela 1, é inacabada. Novos materiais são descobertos a cada dia e novos usos para antigos materiais, alteram sua classificação.

Outra consideração deve ser realizada ao pensarmos em novas tecnologias para gerenciamento da informação. Por exemplo, na construção civil a Modelagem da Informação surge para tentar organizar processor e melhorar a interoperabilidade entre os projetos.

Algumas classificações para elementos e materiais foram desenvolvidas para facilitar esta tarefa: Omniclass (classificação facetada + hierárquica), Uniformat (classificação facetada) e Masterformat (classificação hierárquica). A classificação ominiclass tem por base a norma ISO-120063 (2007) já traduzida para o português, ABNT-NBR-ISO-12006-2 (2010), intitulada "Construção de edificação: Organização de informação da construção - Parte 2: Estrutura para classificação de informação". Esta classificação mescla elementos e componentes a sistemas e conjuntos, fornecendo uma estrutura para base de dados que aborda desde a organização de bibliotecas de materiais e produtos até a organização sobre o projeto.

A estrutura da classificação foi utilizada (embora sem a preocupação com a geração de códigos) para associar os materiais catalogados na materioteca as etapas construtivas e aos sistemas construtivos. Pretende-se reproduzir esta classificação também para produtos.

Para os materiais, as fichas do catálogo apresentam uma breve introdução do material, focando na ACV (Análise do Ciclo de Vida). Seguem conceitos básicos, propriedades, características, um breve histórico do material e tipos principais, classificados de acordo com normas nacionais e internacionais.

A materioteca surgiu num esforço de fornecer informações como subsídios a cerca da sustentabilidade para seleção dos materiais, de forma a permitir uma avaliação por parte dos projetistas. A Tabela 2 traz uma ideia dos comparativos que se espera que a materioteca possa proporcionar.
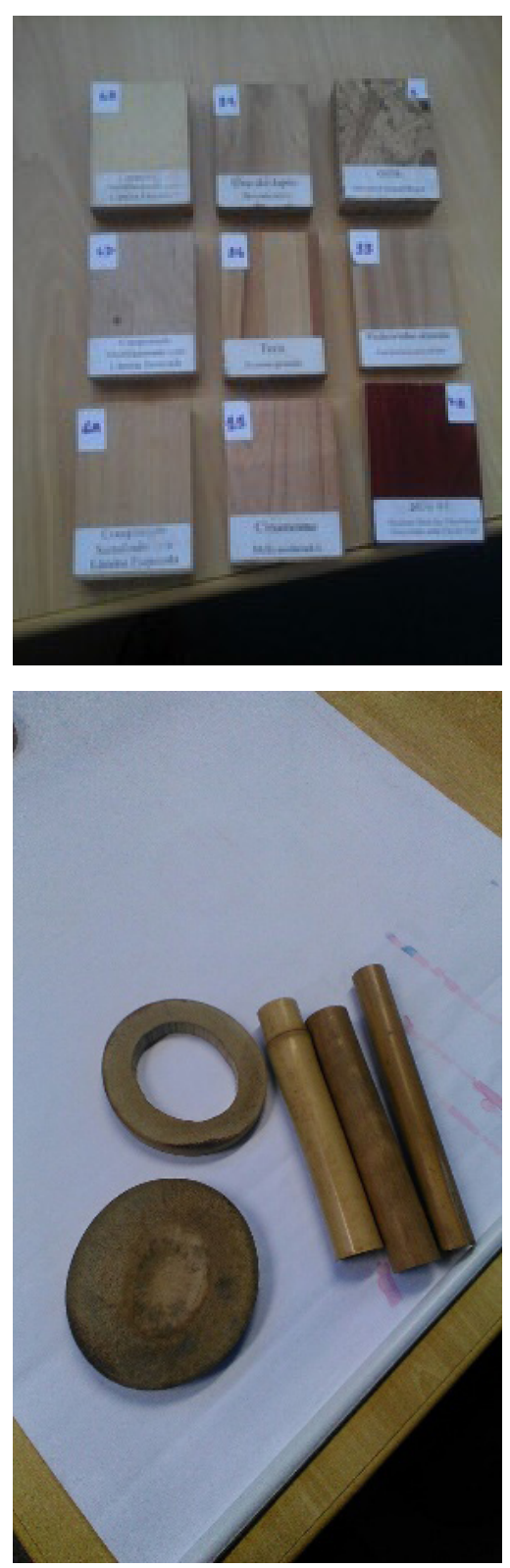

Figura 5 - Exemplo de amostras da materioteca. Fonte: Ferroli e outros (2017) 
Tabela 2 - Comparativo do consumo energético de alguns materiais.

\begin{tabular}{|l|c|c|c|c|}
\hline \multirow{2}{*}{ MATERIAL } & \multicolumn{4}{|c|}{ CONSUMO ENERGÉTICO } \\
\cline { 2 - 5 } & $\begin{array}{c}\text { KWH/ } \\
\text { KG }\end{array}$ & $\begin{array}{c}\text { KWH/ } \\
\mathbf{M}^{\mathbf{3}}\end{array}$ & $\begin{array}{c}\text { KG } \\
\text { EQUIVALENTE } \\
\text { DE CARVÃo }\end{array}$ & $\begin{array}{c}\text { MEGA } \\
\text { J/KG }\end{array}$ \\
\hline Madeira serrada & 0,7 & 350 & 0,8 & $\leq 5$ \\
\hline $\begin{array}{l}\text { Madeira } \\
\text { laminada colada }\end{array}$ & 2,4 & 1200 & n.i. & n.i. \\
\hline Cimento & 1,4 & 1750 & 260 & n.i. \\
\hline Concreto & 0,3 & 700 & 25 & n.i. \\
\hline Tijolo & 0,8 & 1360 & 140 & n.i. \\
\hline Aço & 5,9 & 46000 & 1000 & $\approx 30$ \\
\hline Plástico - PVC & 18 & 24700 & 1800 & n.i. \\
\hline Alumínio & 52 & 141500 & 4200 & $\approx 120$ \\
\hline
\end{tabular}

Fonte: Soares (2011)

De acordo com Quintert e Silveira (2016), para a maioria das regiões da América latina o bambu é um material para construção abundante, econômico e ecológico. Os autores focaram seu estudo na espécie Gradua, devido ao fator de renovação, pois seu crescimento é muito rápido. A resistência deste bambu já foi testada e comprovada, tanto em ensaios laboratoriais como em construções práticas, havendo relatos de edificações de cinco andares construídas com ele.

Os autores também chamaram a atenção para a necessidade de integração entre o design e a arquitetura (ou engenharia). Isso é importante, uma vez que um dos fatores limitantes apontado nas construções com o bambu é a dificuldade de se fazer ligações que funcionem devidamente.

No mercado existem elementos comerciais prontos e que são muitas vezes usados como cabos e fios para amarrações, parafusos e barras roscadas. No entanto, estes não se adaptam muito bem na prática e o 
ideal seria a utilização e peças especialmente projetadas e produzidas com o próprio bambu. As tentativas neste sentido nem sempre são viabilizadas porque envolvem custos elevados e processos complexos de fabricação e montagem.

Carbonari e outros (2017) apresentam resultados de testes em nove espécies de bambu, medindo características mecânicas como resistências a flexão, a tração, a compressão e o módulo de elasticidade longitudinal.

Os autores informam que o bambu possui mais de 1.000 espécies e que pertence a família das gramíneas, o que explica suas características de rápido crescimento ( 3 a 6 meses é suficiente para que um broto atinja a altura máxima, que pode chegar a 30 metros em espécies gigantes). A Figura 5 ilustra uma touceira de um tipo de bambu gigante.

De acordo com Filgueiras e Gonçalves (2004), o Brasil é o País com maior diversidade de espécies de bambu no novo mundo. Em relação aos bambus herbáceos há duas subfamílias, três gêneros e sete espécies, enquanto em relação aos bambus lenhosos há 18 gêneros, sendo que seis são endêmicos e 155 espécies, sendo que $83 \%$ destas são também endêmicas. Os gêneros com maior número de espécies são Merostachys Spreng (53 espécies) e Chusquea (40 espécies). Ao todo são 34 gêneros e 232 espécies no Brasil, sendo que algumas ainda não foram formalmente descritas, além de 174 espécies (75\%) serem consideradas endêmicas.

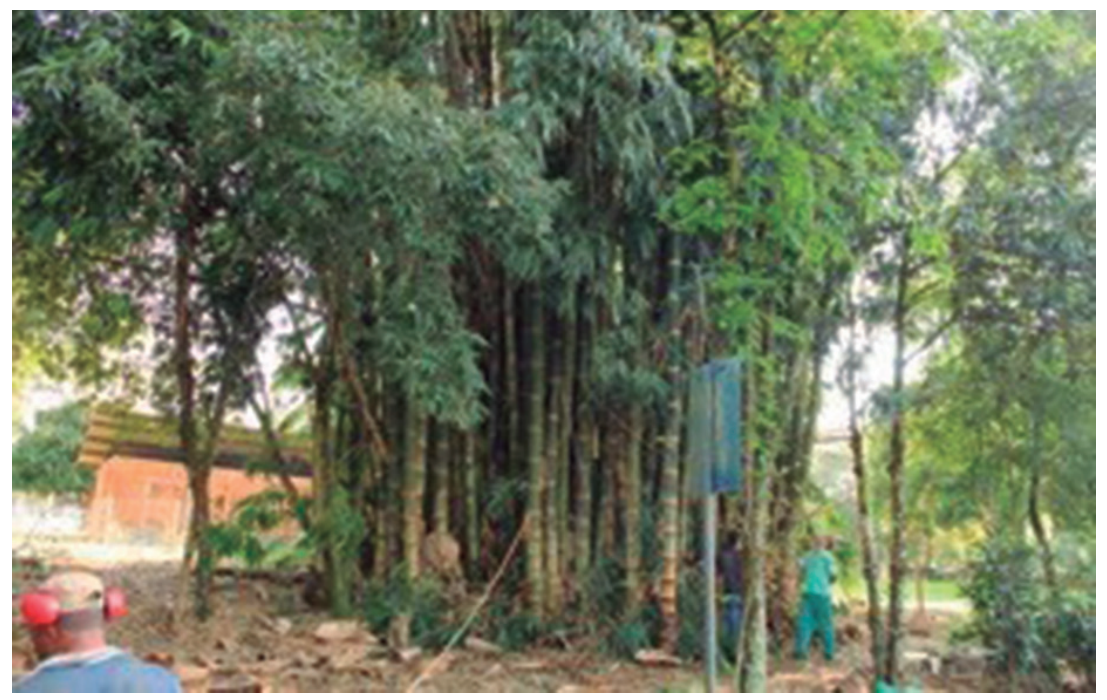

Figura 6: Bambuzal da Universidade Estadual de Londrina. Fonte: Acosta; Carbonari (2017). 
A classificação proposta dos bambus é muito variada, atingindo mais de 1.000 espécies, enquanto outros afirmam existirem em torno de 85 espécies (com subespécies) e outros ainda falando sobre algo em torno de 500. A explicação é que alguns estão levando em consideração as sub-espécies. Por exemplo, a espécie Bambusa, possui mais de 40 subespécies catalogadas. Destas, pelo menos quatro são recomendadas para projeto estrutural: Bambusa Beecheyana, Bambusa Oldhamil, Bambusa Nutans e Bambusa

Vulgaris. Estas quatro foram consideradas no estudo de Carbonari e outros (2017) e são as que apresentam os melhores índices de resistência a compressão e flexão.

Os autores também apresentam ótimos resultados obtidos em testes laboratoriais, e descrevem as mesmas dificuldades apontadas por Quintana e Silveira (2016) a respeito das conexões estruturais que impedem ou pelo menos dificultam a utilização do material em larga escala. Padaven (2010) apudapudapud Carbonari e outros (2017) explicam que a ausência de projetos adequados de ligações, diferentemente do que ocorre com materiais tradicionais como madeira e aço (com boa oferta de elementos de ligação já testados), impede o aproveitamento pleno das potencialidades de uso do bambu.

Alguns fatores como o teor de umidade, o solo e o clima, idade e época da colheita afetam a resistência mecânica do bambu, que já varia bastante conforme a variedade de espécies. Desta forma o bambu é considerado como uma planta lenhosa. Possui uma parte aérea (colmo) e outra parte subterrânea (rizoma e raízes).

Os colmos geralmente são ocos, de forma cilíndrica e dispõe de "uma sequência de entrenós (internós), separados transversalmente uns dos outros por diafragmas (septos), que aparecem externamente como nós, de onde saem ramos e folhas, dispostos alternadamente. Os diafragmas fornecem maior rigidez e resistência aos colmos, permitindo-Ihes suportar a ação do vento e do peso próprio." (PEREIRA e BERALDO, 2007). 


\section{CONHECIMENTO SOBRE BAMBU - NORMAS TÉCNICAS AO REDOR DO MUNDO E REDES CONSTITUÍDAS}

O INBAR (1999) - International Network for Bamboo and Rattan - a partir dos resultados de pesquisas mundiais propôs normas para os ensaios de caracterização das propriedades físicas e mecânicas dos bambus. As normas foram analisadas pela International Conference of Building Officials (ICBO) e publicadas no relatório AC 162: Acceptance Criteria for Structural Bamboo, em março de 2000 (ICBO, 2000).

Conforme Ghavami e Marinho (2005) para ensaios com bambu na sua forma natural (cilíndrica), recomenda-se usualmente a utilização das normas ISO N 313 (Bamboo Structural Design), ISO 314 (Physical and Mechanical Properties) e ISO 315 (Testing Material).

O Brasil ainda não dispõe de norma técnica que verse sobre o uso deste material, mesmo que ele esteja presente na história deste país. No Mundo, as seguintes normas foram encontradas, utilizando o guia de buscas da World Standars Index. Da relação de normas, foram excluídas as normas relativas a fabricação de palitos descartáveis (pauzinhos/varetas/ hashi) e do bambu em conserva para alimentos, diga-se de passagem, presente em grande número nas normas internacionais.

- ISO 22156-2004 Bamboo - Structural design - aplica-se ao uso de estruturas de bambu, ou seja, estruturas feitas de bambu (bambu roliço, bambu dividido, bambu laminado colado) ou painéis de bambu unidos com adesivos ou fixadores mecânicos. Baseia no projeto considerando o estado limite e no desempenho da estrutura. Preocupa-se com os requisitos de resistência mecânica, manutenção e durabilidade das estruturas.

- ISO/TR 22157-2 - Parte 2 Bamboo - Determination of physical and mechanical properties -- Manual de laboratório.

- ISO/TR 22157-1 - Parte 1 Determination Of Physical And Mechanical Properties - Part 1: Requirements Este padrão é organizado para fornecer requisitos claros para testes padrão 
a serem realizados para determinar as propriedades do bambu como material de construção ou engenharia.

- LY/T 1072-2002 - Bamboo thin bamboo strip accumulates plywood technology condition. Este padrão especifica os requisitos técnicos do bambu utilizado em contraplacados (Plywood), regras e itens de inspeção, embalagem, transporte e armazenamento.

- DB51/T 1789.1-2014 Bamboo product - partes 1 a 7 contendo uma série de esepecificações para ensaios de produtos em bambu.

- DB51/T 1813-2014 - Bamboo weaving production technology procedures Planar bamboo weaving - tecnologia de produção para tecelagem com bambu.

Outras normas também foram encontradas para cultivo, planejamento do cultivo e de jardins utilizando algumas espécies de bambu.

Ainda, foram encontradas diversas normas em Chinês (sem tradução para outras línguas), referente a tecnologias de fabricação de componentes em bambu.

No Brasil estão sendo realizados esforços para disseminação e desenvolvimento da cultura do bambu. Desta forma foram instituídas:

- Rede Brasileira de Bambu e desmembramentos estaduais;

- REBASP (Rede do Bambu de São Paulo);

- BAMBUSC (Rede do Bambu de Santa Catarina);

- AGABAMBU (Rede Gaúcha do Bambu); APROBAMBU (Associação Brasileira dos Produtores de Bambu);

- ABMTENC (Associação Brasileira em Materiais e Tecnologias não Convencionais);

- INBAMBU (Instituto do Bambu - Alagoas); e

- ABC (Agencia Bambu do Conhecimento).

- Internacionalmente pode-se citar:

- INBAR - Rede Internacional para o Bambu e o Ratim;

- WBO - Organização Mundial do Bambu; e

- ABS - Associação Americana de Bambu e Associação Australiana de Bambu. 
- Ainda, podem-se cadastrar grupos/centros de pesquisa de pesquisa e projetos tratando do tema:

- EBIOBAMBU (Escola de Bioarquitetura e Centro de Pesquisa e Tecnologia Experimental em Bambu), localizada em Visconde Mauá (RJ);

- CPAB (Centro de Pesquisa e Aplicação de Bambu), na UnB Brasília (DF);

- CCT Bambu (Centro de Capacitação Tecnológica em Bambu);

- Projeto Bambu de Unesp, em Bauru (SP);

- Grupo de Pesquisa VirtuHab - UFSC, Florianópolis (SC);

- Projeto Cantoar - Canteiro, Oficina de Arquitetura e Fibras Naturais (FAU/UnB);

- Casa Eco - Instituto de Pesquisa da Amazônia (INPA);

- Instituto Tibá, Rio de Janeiro (RJ);

- Bambuzeria Cruzeiro do Sul (Bamcrus), Belo Horizonte (MG);

- Programa de Desenvolvimento Integrado do Bambu, Mato Grosso do Sul (MS);

- Agência Bambu de Conhecimento (RJ);

- Bambuzal Bahia (BA); e

- Bambuzal Alagoas (AL)

Manhães (2008) traz em sua pesquisa sobre a cadeia produtiva do bambu, uma lista de Institutos e Universidades que pesquisam o bambu e fomentam sua cultura e plantio. 0 trabalho com o bambu está disperso em várias associações e programas de pós-graduação que, por vezes, possuem pouca divulgação. A proposição das redes de pesquisa em bambu pode auxiliar na divulgação destes trabalhos.

\section{MÉTODO DE PESQUISA}

Esta pesquisa se fundamenta na busca de bibliografias sobre o material bambu, na tentativa de mapear as principais contribuições ao tema. Desta forma estruturou-se sua classificação, características do material, descrição básica da cadeia produtiva no Brasil, principais autores e assuntos de pesquisa, normas técnicas mundiais e principais institutos e associações que pesquisam o material. 
Pesquisou-se no banco de teses e dissertações da CAPES, em 26/09/2017, como o tem do bambu, refinando-se a busca para publicações de até 2010 e encontrou-se inicialmente 262 trabalhos defendidos no tema. Refinou-se a busca por orientador, considerando no mínimo 3 trabalhos orientados no tema. A busca a partir deste filtro resultou em 4633 pesquisas defendidas, sendo destas 40 são dissertações e 6 teses.

Os temas encontrados nestas teses e dissertações foram: uso do bambu no design de joias (1), design de conexões estruturais (1), tratamento do bambu (3), painéis (2), forragens para animais (1), concreto reforçado com bambu (2), análise estrutural do Bambu empregado em estrutura (1), desempenho estrutural do bambu em relação a esforços (1), emprego de materiais locais na construção (1), bambu laminado colado (4), estruturas treliçadas leves de bambu (1), eco-design em calçados (1), florestas de bambu (7), carvão vegetal (2), bio-óleo (1), desempenho de reatores anaeróbios com meio suporte de bambu (5), design de móveis (1), sem relação com o tema (5); biodiversidade (6).

\section{CADEIA PRODUTIVA DO BAMBU}

Para que seja possível alcançar a sustentabilidade do emprego do bambu é preciso integrar todas as fases da cadeia produtiva e incentivar as boas práticas: manejo das plantações, utilização de resíduos da poda, preservação natural (preferencialmente sem agredir o meio ambiente e a saúde humana), equipamentos eficientes para o beneficiamento e produção de materiais primários, semi-elaborados ou de maior valor agregado e por fim, a comercialização e uso dos componentes na produção habitacional.

A representação da cadeia produtiva pode ser encontrada na Figura 7. No Brasil algumas cadeias produtivas conseguiram se desenvolver, a saber: Grupo João Santos (fabricação de papel), a partir da criação do bambusa vulgaris. Venda de mudas de bambus ornamentais e a produção de bambus para envasamento na indústria alimentícia. 


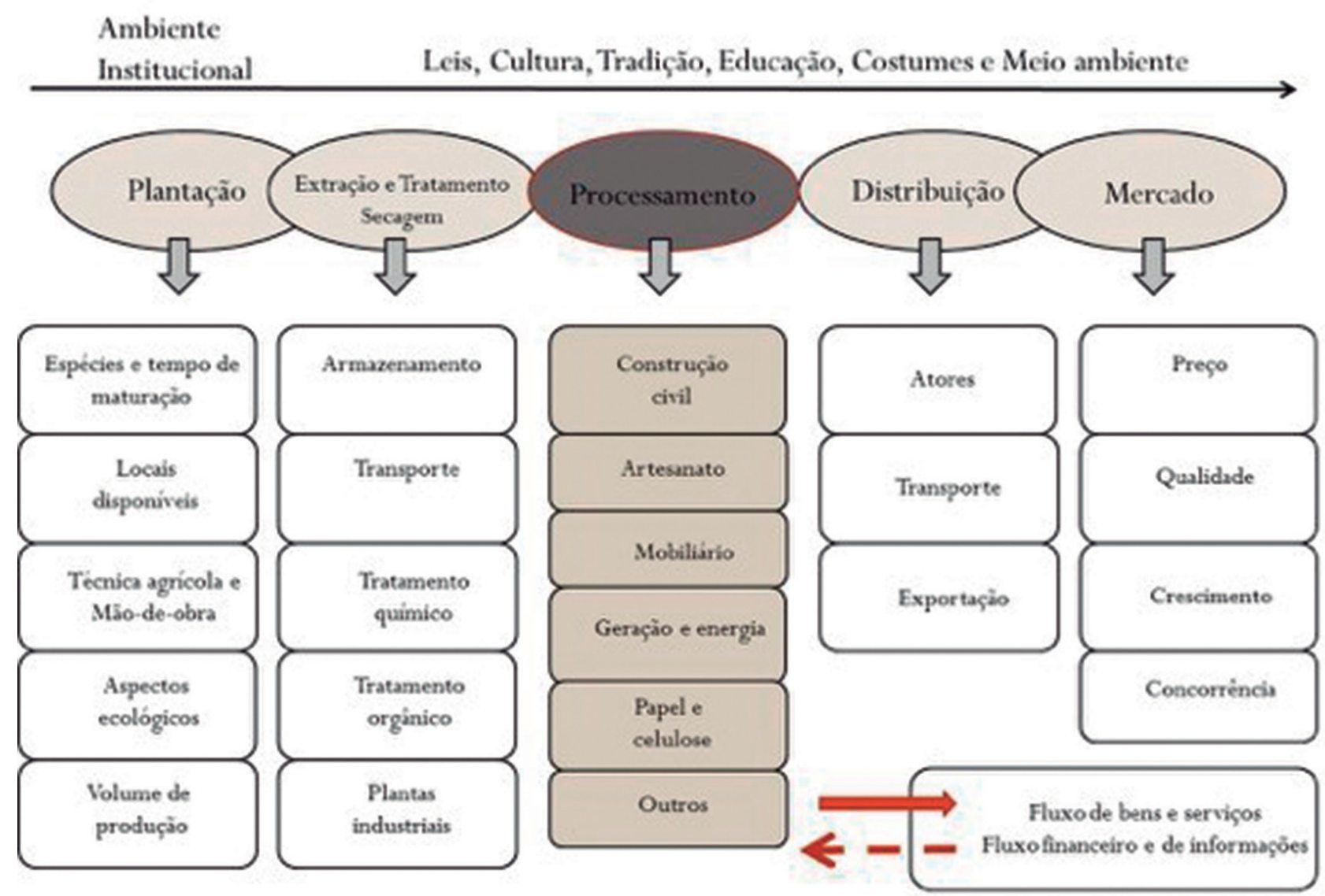

\section{Ambiente} organizacional
Associações, cooperativas, infraestrutura, informações, organizações de apoio, financiamento, pesquisa e desenvolvimento tecnológico

Pesquisadores têm estudado as etapas desta cadeia, dispondo de valioso conhecimento específico para viabilizar o emprego de bambu, logicamente, dentro de suas áreas de conhecimento. Assim a viabilidade do emprego do bambu como material requer a atuação interdisciplinar dos agentes, nas etapas da cadeia:

- Silvicultura - produção do bambu no viveiro, plantação e identificação de touceiras naturais.

Figura 7: Cadeia produtiva do bambu. Fonte: Dantas (2017). 


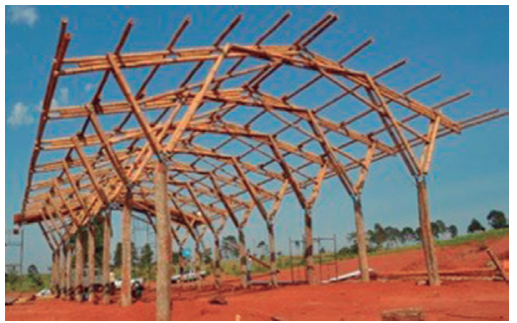

Figura 8 - Galpão em bambu do grupo Viverde. Fonte: Barata (2017).
- Colheita e pós-colheita - determinação da idade, data e hora para colheita; limpeza e retirada das folhas, empilhamento e transporte; preservação, armazenamento e conservação.

- Usos e processos de transformação - produtos/usos primários (com bambu roliço e produtos naturais fracionários); Produtos semielaborados (esteiras, pisos e laminados); produtos de maior valor agregado (esquadrias, painéis, treliças para coberturas, entre outros).

- Comercialização e consumo - rede de distribuição para comercialização dos componentes fabricados, estratégias de comercialização e possibilidades de emprego em produtos complexos.

- Projeto e construção - o projeto deve envolver habitações sustentáveis modulares, considerando os princípios da construtibilidade, manutenibilidade e racionalidade construtiva. Deve ainda considerar no layout a flexibilidade e funcionalidade dos ambientes. Deve utilizar materiais de baixo impacto ambiental, facilmente obtido na região, que não provoquem danos à saúde humana ou de animais, economicamente viável e que de preferência possa desenvolver social e economicamente a região onde será implementada.

\section{PROJETOS EM BAMBU: PANORAMA GERAL}

Conforme visto anteriormente, o bambu tem se destacado como material alternativo em projetos de arquitetura, engenharia e design. Muitos dos estudos mostrados anteriormente neste artigo deixam claro o quanto é importante a interdisciplinaridade, especialmente pelas características novas do material e da, ainda, falta de confiabilidade dos dados disponíveis, muitas vezes oriundas de experimentação amadora, sem rigor científico.

Embora exista consenso das potencialidades do material, muitas dúvidas ainda persistem. 0 bambu é utilizado tanto in natura quanto processado. A Figura 8 mostra o projeto do galpão da oficina da Associação Agroecológica Viverde, localizado em Pederneiras (SP), onde se utilizou - Bambu in natura da espécie Dendrocalamus asper e a Figura 9 mostra projeto de mobiliário desenvolvido pelo mesmo grupo. (BARATA, 2017). 
Os mais diversos produtos podem se utilizar do bambu como matéria-prima. Há desde compotas em bambu (como na indústria alimentícia), fabricação de palitos de dente, canetas, mobiliários, painéis decorativos, bicicletas, skates, teclados para computadores, talheres, pentes, escovas de dentes, pratos, redes, brinquedos e óculos.

Martins \& Guerreiro (2006) mapearam diversos usos do bambu no Brasil: agricultura, produção de biomassa, carvão, culinária, produção de compensado (contraplacados), na construção civil, produção de móveis,

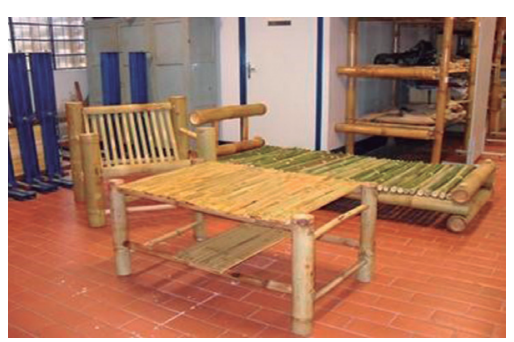

Figura 9: Mobiliário em bambu do grupo Viverde. Fonte: Grupo Viverde (2017). papel e produtos diversos como luminárias, palitos de dente, hashis, embalagens, canetas e até bicicletas.

No que se refere à construção de edificações, alternativas devem ser promovidas para viabilizar a construção de moradias mais sustentáveis. Considerando o déficit habitacional brasileiro divulgado pela Fundação João Pinheiro (2015) de 6.198.294 milhões de moradias seriam necessários 363,46 milhões de metros quadrados construídos, pensandose na construção de habitações isoladas de área real total de $58,64 \mathrm{~m}^{2}$.

Para se ter uma ideia de consumo de recursos para construção da metragem quadrada total de casas para resolver o déficit habitacional brasileiro, considerando uma construção em sistema construtivo constituído por concreto armado e alvenaria de vedação, conforme estabelecido no projeto-padrão R1B pela NBR 12721 (2006) com os insumos definidos no seu lote básico, seriam necessários os consumos:

- Aço $=6.642 .573 .242 \mathrm{~kg}$ (30 MJ/kg de energia e $1,45 \mathrm{~kg} / \mathrm{kg}$ de $\mathrm{CO}_{2}$ )

- Concreto= $95.079 .584 \mathrm{~m}^{3}\left(2760 \mathrm{MJ} / \mathrm{m}^{3}\right.$ de energia)

- Areia $=62.745 .474 \mathrm{~m}^{3}\left(80 \mathrm{MJ} / \mathrm{m}^{3}\right.$ de energia e $48,68 \mathrm{~kg} / \mathrm{sc}$ de $\left.\mathrm{CO}_{2}\right)$

- Cimento total $=665.557 .086 \mathrm{sc}$ (concreto) $+409.982 .845 \mathrm{sc}$ (argamassa) - (210MJ/sc de energia e $48,44 \mathrm{~kg} / \mathrm{sc}$ de $\left.\mathrm{CO}_{2}\right)$

- Tijolos = 21.291.469.684 un $\left(4060 \mathrm{MJ} / \mathrm{m}^{3}\right.$ e de energia e 0,98 kg/ un de $\mathrm{CO}_{2}$ )

Desta forma, pode-se perceber o nível de impacto ambiental e consumo de recursos só para resolver o problema brasileiro. Esse fato enfatiza a necessidade de diversificação da tecnologia e sistema construtivo, sendo o bambu uma das alternativas com grande potencial de aproveitamento. Analisando a questão das emissões, o bambu, não só possui baixa emissão, mas também atua como um sequestrador de carbono. 
Na construção de edificações o bambu pode ser utilizado com diversos fins, como: pilares, vigas e treliças, painéis de vedação verticais (taipas, esterilhas, bambucreto, painéis com calfitice), painéis decorativos, esquadrias, estrutura de telhados, telhas, escadas artesanais, ligações e conexões, construção de galpões, casas de vegetação, viveiros e abrigos de animais, galpões, cercas, postes, elementos e componentes laminados, e elementos e componentes planificados.

\section{CONSIDERAÇÕES FINAIS}

O bambu é um excelente material, pois é resistente, leve, atua no sequestro de carbono, é renovável e disponível no Brasil. Entretanto, a variabilidade das espécies e conhecimento necessário para seu emprego requerem ainda muita pesquisa e divulgação.

Tornar o bambu um material de maior durabilidade nos projetos contemporâneos é um desafio. Requer o desenvolvimento de uma cadeia produtiva que vá desde o cultivo, extração, fornecimento de peças e componentes, comercialização com a descrição de características, que permitam o conhecimento da espécie, características de tratamento, região de produção, idades, entre outros.

Sobretudo a promulgação de normas técnicas abordando as espécies prioritárias e desenvolvimento de equipamentos de pequeno porte pode contribuir de forma desigual para o seu uso em produtos e edificações.

\section{REFERÊNCIAS}


CARBONARI, Gilberto; SILVA JÚNIOR, Nelson M. da; PEDROSA, Nicolas Henrique; ABE, Camila Hiomi; SCHOLTZ, Marcos Ferreira; ACOSTA, Caio Cesar Veloso; CARBONARI, Luana Toralles. Bambu - o aço vegetal. Mix Sustentável v. 3, n. 1, set.-mar. 2017, p. 17-27.

CHIAVERINI, Vicente. Aços e ferros fundidos. 7. ed. São Paulo: ABM, 2012.

DANTAS, Anderson Barros; MILITO, Cláudia Maria; LUSTOSA, Maria Cecília Junqueira. O uso do bambu na construção do desenvolvimento sustentável. Maceió: Instituto do Bambu, 2005.

FERROLI, Paulo Cesar Machado; LIBRELOTTO, Lisiane Ilha; VIDIGAL, Maria Fernanda; SETTER, Diogo Alessandro. Sistema de leitura integrada amostras - site para classificação de materiais em uma materioteca interdisciplinar. V ENSUS - Encontro de Sustentabilidade em Projeto. Florianópolis, UFSC, 2-4 de maio, 2017. Anais, p. 318-327.

FILGUEIRAS, T. S.; GONÇALVES, A. P. S. A. Checklist of the Basal Grasses and Bamboos in Brazil (POACEAE). Bamboo Science and Culture: The Journal of the American Bamboo Society 18(1):

7-18. 2004

GHAVAMI, K.; MARINHO, A. B. Propriedades físicas e mecânicas do colmo inteiro do bambu da espécie Guadua angustifolia. Revista Brasileira de Engenharia Agrícola e Ambiental, v. 9, n. 1, p. 107-114, 2005

GREAY, Theodore. Os elementos: uma exploração visual dos átomos conhecidos no universo. São Paulo: Blucher, 2011.

INBAR. The international network on bamboo and rattan. International model building code for bamboo. 1999

LEFTERI, Chris. Materiais em design - 112 materiais para design de produtos. Blucher: São Paulo, 2017.

MANHÃES, A. P. Caracterização da cadeia produtiva do bambu no Brasil: abordagem preliminar. Monografia curso de Engenharia Florestal. Instituto de Florestas. UFRRJ. 2008

PEREIRA, Andrea Franco. Madeiras brasileiras - guia de combinação e substituição. São Paulo: Blucher, 2013.

PEREIRA, Marco Antonio dos Reis; BERALDO, Antonio Ludovico; FEFFER, Betty (colaboradora). Bambu de corpo e alma. São Paulo, 2007.

QUINTERO, Carlos Andrés Sánchez, SILVEIRA, Wilson Jesus da Cunha. Desenvolvimento de uma ligação estrutural para construção com bambu Gradua. Mix Sustentável, v. 2, n. 1, abr. set. 2016, p. 98-106

SENAI-SP. Madeira - matéria-prima para o design. São Paulo: Senai, 2014

SOARES, Sebastião; FRÓES BRANDÃO, de Sousa Soares. Estruturas em bambu. Dissertação de mestrado. UFOP. Portugal. 2013.

ORGANIZAÇÃO MUNDIAL DO BAMBU. Disponivel em: <http:/www.worldbamboo.net>. Acesso: Junho de 2017.

https:/www.livrariadoplastico.com

https:/www.facebook.com/grupoviverde

https:/www.grantadesign.com.

http:/www.arandanet.com.br/revista/pi

http:/flyingmachines.ru/Site2/Crafts/Craft28568.htm

http:/anaveraldo.blogspot.com.br/2011/03/construcao-tradicional-indigena.html

Arquitetura do Brasil. http:/arquitetofala.blogspot.com.br/2011/12/arquitetura-indigena-nobrasil.html. 
